九州大学学術情報リポジトリ

Kyushu University Institutional Repository

\title{
Intracerebroventricular injection of orexin-A stimulates monoamine metabolism but not HPA axis in neonatal chicks
}

Katayama, Sachiko

Laboratory of Regulation in Metabolism and Behavior, Graduate School of Bioresource and Bioenvironmental Sciences, Kyushu University

Shigemi, Kazutaka

Laboratory of Regulation in Metabolism and Behavior, Graduate School of Bioresource and Bioenvironmental Sciences, Kyushu University

Cline, Mark A. Laboratory of Regulation in Metabolism and Behavior, Graduate School of Bioresource and Bioenvironmental Sciences, Kyushu University

Furuse, Mitsuhiro

Laboratory of Regulation in Metabolism and Behavior, Graduate School of Bioresource and Bioenvironmental Sciences, Kyushu University

http://hdl. handle. net/2324/26042

出版情報: Neuroscience Letters. 484 (2)，pp.157-161，2010-10-29. Elsevier バージョン：

権利関係: (C) 2010 Elsevier Ireland Ltd. 


\section{Intracerebroventricular injection of orexin-A stimulates monoamine metabolism but not HPA axis in neonatal chicks}

Sachiko Katayama, Kazutaka Shigemi, Mark A. Cline ${ }^{1}$ and Mitsuhiro Furuse*

Laboratory of Regulation in Metabolism and Behavior, Graduate School of Bioresource and Bioenvironmental Sciences, Kyushu University, Fukuoka 812-8581, Japan

${ }^{1}$ Department of Biology, PO Box 6931, Radford University, Radford, Virginia, 24142, United States

*Correspondence to: M. Furuse, PhD, Laboratory of Regulation in Metabolism and Behavior, Graduate School of Bioresources and Bioenvironmental Sciences, Kyushu University, Fukuoka 812-8581, Japan.

E-mail address: furuse @brs.kyushu-u.ac.jp

Phone \& Fax: +81-92-642-2953

Keywords:

orexin-A

neonatal chicks

corticosterone

norepinephrine

dopamine 
serotonin 


\begin{abstract}
We investigated the effects of intracerebroventricular (ICV) injection of orexin-A on plasma corticosterone (CORT) concentration and brain monoamine metabolism to clarify the mechanism by which ICV orexin-A induced arousal in chicks. In Experiment 1, plasma CORT concentrations were measured as an indicator of hypothalamic-pituitary-adrenal (HPA) axis activity. There was no significant difference in CORT concentration between the control and orexin-A administered groups. In Experiment 2, the concentrations of monoamines (norepinephrine, dopamine and serotonin), their metabolites, and their metabolic turnover rates in the telencephalon, mesencephalon, and diencephalon were investigated. All metabolic turnover rates studied were increased at all brain sites after ICV orexin-A injection. In conclusion, the HPA axis does not appear to be involved in arousal-inducing mechanisms of orexin-A in neonatal chicks; however, several monoaminergic systems do.
\end{abstract}


Orexin-A and -B are peptidergic neurotransmitters that were first isolated through a search for ligands of previously orphan receptors now identified as OX1 and OX2 [30]. Orexin-A and -B are alternatively known as hypocretin-1 and hypocretin-2, respectively, because they are found in the hypothalamus and are related to the incretin family of neurotransmitters [17]. Since their isolation over a decade ago, the orexins have been implicated in a few processes including food intake and energy expenditure. In addition, the orexins are most noted for their roles in wakefulness: central injection of orexin induces arousal, activity and decreases non-rapid eye movement (REM) and REM sleep [8]. Recent evidence supports that orexins are important mediators of sleep/wake cycles. However, most reports on orexins are based on rodent studies.

Our group has tested the orexins in two stocks of chicks: layers (egg-type) and broilers (meat-type). We demonstrated that under ad lib feeding, orexin-A did not affect food intake and orexin-B was associated with decreased food intake of broiler chicks [7]. More recently, we have demonstrated that orexin-A increased arousal in layer, but not in broiler chicks, and that orexin-B is not likely involved in sleep/wake cycles [12]. Possible mechanisms associated with these behavioral differences may involve the hypothalamic-pituitary-adrenal (HPA) axis and/or activation of monoamine neurons.

The HPA axis is activated under stressful conditions in chicks [6]. With activation of this axis, corticotropin-releasing factor (CRF) in the hypothalamus induces the release of adrenocorticotropic hormone (ACTH) in the pituitary, which enhances release of corticosterone (CORT) from the adrenal cortex. Orexins may be related to the stress response [5]. Increased plasma ACTH and CORT after central administration of orexin suggests that orexin activates the HPA axis in rats [28]. Alternatively, CRF-containing neurons conversely innervates orexin neurons [37]. Arousal mechanisms of orexin-A in neonatal chicks are unreported, but we thought that the behavioral differences after orexin-A administration may contribute to 
activation of the HPA axis. Saito et al. [29] demonstrated that plasma corticosterone concentrations after the ICV injection of CRF were significantly higher in layers than broilers. Recently, the differences between layers and broilers were suggested to be due to differential regulation of the HPA axis, but not synthesis of associated neuropeptides [36].

The relationships between orexins and monoamines are reported by many researchers (reviewed by Ohno and Sakurai [26]). Orexin neurons innervate many areas of the brain that are important in the activity of each monoamine. The locus coeruleus (LC) has a dense concentration of norepinephrine (NE), the dorsal raphe nucleus (DRN), and median raphe nucleus (MRN) are areas with high serotonin (5-HT) concentration, and the brain stem is where orexins are synthesized and also has an abundant concentration of dopamine (DA) [13]. NE and 5-HT are known as waking-active, and their activity is different depending on sleep status [31]. In the state of vigilance, orexins stimulate these monoamines to keep animals awake, and have a suppressed firing rate [26]. However, to our knowledge there is no report of relationships between the orexins and monoamines to explain the arousal effect of orexin-A in layer neonatal chicks.

As a primary step in the investigation of mechanisms of arousal by orexin-A, we studied the effects of central injection of orexin-A on blood CORT (Experiment 1) and brain monoamine contents in neonatal chicks (Experiment 2). The structure of orexin peptides is highly conserved between different mammalian species [30]. According to Ohkubo et al. [24], chicken orexin-A and orexin-B showed approximately $85 \%$ and $65 \%$ similarities with the corresponding mammalian sequence at the amino acid level. Katayama et al. [12] reported that mammalian orexin-A was functioned and increased arousal in chicks. We also applied mammalian orexin-A in the preset study.

Day-old male layer chicks (Julia) were purchased from local hatchery (Murata Hatchery, Fukuoka, Japan). The chicks were maintained in a windowless room at the 
temperature of $30 \pm 1^{\circ} \mathrm{C}$ with continuous lighting. They were given free access to a commercial starter diet (Toyohashi Feed and Mills Co. Ltd., Aichi, Japan) and water unless otherwise mentioned. When they were divided into groups for experiments, body weights were distributed uniformly across groups. Experimental procedures followed the guidelines set forth by the Animal Experiments in Faculty of Agriculture, the Graduate Course of Kyushu University, Japanese Law No. 105 and Notification No. 6 of the Japanese Government.

Chicks were ICV injected with human orexin-A (Peptide Institute, Osaka, Japan) dissolved in vehicle solution at a volume of $10 \mu \mathrm{l}$ using a microsyringe according to the method of Davis et al. [4]. The stress and discomfort by this method is minimal as described elsewhere $[7,15]$. The vehicle consisted of $0.85 \%$ saline containing $0.1 \%$ Evans blue that was made on the day of the experiments. At the end of the experiments, birds were sacrificed by cervical dislocation after which the location of the injection site was confirmed. Any chicks without Evans blue dye in the lateral ventricle were eliminated from analysis.

In Experiment 1, layer chicks (5 day-old) were acclimated to individual cages for 1 day prior to the experiment. Chicks were ICV injected with vehicle (control) or 2 nmol orexin-A. Jugular blood was collected at 30 and 60 min after injection and was immediately treated with heparin, then centrifuged at $11,000 \times \mathrm{g}, 4^{\circ} \mathrm{C}$ for $4 \mathrm{~min}$. Plasma samples were stored at $-80^{\circ} \mathrm{C}$ until analysis. Plasma CORT was determined using a corticosterone enzyme immunoassay kit (Assay Designs Inc., USA).

In Experiment 2, layer chicks (6 day-old) were acclimated to individual cages 1 day before the experiment. They were ICV injected with either vehicle (control) or 2 nmol orexin-A according to the previous studies [7, 12]. At 30 and 60 min after injection, the whole brain was rapidly removed, and was dissected into three parts according to the atlas of the chicken brain [16]: mesencephalon, telencephalon and diencephalons. Diencephalon was divided by cutting between stria medullaris and 
posterior commissure. Mesencephalon was separated by cutting connective tissue in the posterior commissure. They were immediately removed, weighed, and kept at $-80^{\circ} \mathrm{C}$ until analysis.

The concentrations of monoamines and their metabolites (contents/g wet tissue) were analyzed by modified method based on Kabuki et al. [11]. Briefly, the tissue was homogenized in $0.2 \mathrm{nmol} / 1$ perchloric acid containing $100 \mu \mathrm{M}$ EDTA $2 \mathrm{Na}$. The homogenate was left for $30 \mathrm{~min}$ to allow complete deproteinization. Then, the homogenate was centrifuged at $20,000 \times \mathrm{g}$ for $15 \mathrm{~min}$ at $0^{\circ} \mathrm{C}$. After centrifugation, the $\mathrm{pH}$ of the supernatant was adjusted to approximately 3.0 by adding $1 \mathrm{M}$ sodium acetate. The supernatant was then centrifuged with a centrifuge-filtration unit (Ultra Free C3-GV Millipore, Bedford, USA) at $10,000 \times \mathrm{g}$ for $5 \mathrm{~min}$ at $0^{\circ} \mathrm{C}$. A $30 \mu \mathrm{l}$ portion of filtrate was applied to a high-performance liquid chromatography system (Eicom, Kyoto, Japan) with a $150 \times 3.0 \mathrm{~mm}$ octadecyl silane column (SC-50DS, Eicom) and an electrochemical detector (ECD-300, Eicom) at an applied potential of $+0.75 \mathrm{~V}$ versus $\mathrm{Ag} / \mathrm{AgCl}$ reference analytical electrode. Changes in electric current (nA) were recorded in a computer using an interface system (Power Chrom ver 2.3.2.j; AD Instruments, Tokyo, Japan). The mobile phase consisted of $100 \mathrm{mM}$ aceto-citric acid buffer ( $\mathrm{pH} 3.5)$, methanol, $460 \mathrm{mM}$ sodium 1-octane sulfonate, and $15 \mathrm{mM}$ disodium ethylenediaminetetraacetic acid (830:170:1.1:1) at a flow rate of $0.5 \mathrm{ml} / \mathrm{min}$. The concentrations of monoamines and metabolites including NE, DA, 5-HT, the NE metabolite 3-methoxy-4-hydroxyphenylglycol (MHPG), DA metabolite 3,4-dihydroxyphenylacetic acid (DOPAC) and 5-HT metabolite 5-hydroxyindoleacetic acid (5-HIAA) were determined, and their concentrations in each brain region were calculated. Turnover rate of each monoamine (DOPAC/DA, MHPG/NE, and 5-HIAA/5-HT) were also calculated. The limit of detection of the system for all monoamines was $0.1 \mathrm{pg} / \mathrm{sample}$.

Plasma concentration of CORT (Experiment 1) and concentration of brain 
monoamines, their metabolites and turnover rates (Experiment 2) were analyzed by two-way ANOVA followed by t-test when significant interactions were observed. As for 5-HT in the mesencephalon and telencephalon, data were partly lost due to equipment failure so unpaired t-test were conducted for 5-HT, 5-HIAA concentrations and their turnover rates. Significant differences imply a $\mathrm{p}$ value of less than 0.05 . Statistical analysis was conducted using a commercially available package: StatView (version 5, SAS Institute, Cary, USA, 1998).

In Experiment 1, there was no significant difference between control and orexin groups after ICV injection of orexin-A on the concentration ( $\mathrm{ng} / \mathrm{ml})$ of plasma corticosterone (vehicle $30 \mathrm{~min} ; 4.403 \pm 0.609$, orexin-A $30 \mathrm{~min} ; 4.722 \pm 0.851$, vehicle $60 \mathrm{~min} ; 4.903 \pm 0.491$, orexin-A $60 \mathrm{~min} ; 4.999 \pm 0.705)[\mathrm{F}(1,25)=0.095, \mathrm{P}=0.7611]$.

For Experiment 2, Tables 1 to 3 show the effect of ICV injection of orexin-A on monoamine metabolism in each brain region: concentrations of monoamines, their metabolites and metabolic turnover rates. Results obtained from diencephalons are shown in Table 1. Compared to controls, NE concentrations were significantly decreased by orexin-A and by time. MHPG was not changed. The metabolic turnover rate, MHPG/NE, was significantly increased in the orexin-A administered groups but was not affected by time. DA concentration was significantly decreased in orexin-A treated groups and by time. DOPAC was significantly decreased by time, but no effect of orexin-A was observed. DOPAC/DA was significantly increased by orexin-A but was not affected by time. 5-HT was significantly decreased in the orexin-A treated groups and by time. 5-HIAA was significantly increased by orexin-A, and the magnitude of this increase tended to decrease as time progressed. 5-HIAA/5-HT was increased both by orexin-A and time.

There were some significant changes in monoamine concentrations in the mesencephalons as well (Table 2), but not for NE. However, MHPG was significantly increased by both orexin-A and time. MHPG/NE was increased by both 
orexin-A and time. DA concentrations were not affected, and although DOPAC concentration was not affected by orexin-A, they did increase over time. DOPAC/DA concentrations were significantly increased by orexin-A treatment and time. 5-HT was not different at $30 \mathrm{~min}$ after injection, but 5-HIAA was increased over time and after orexin-A treatment. The 5-HIAA/5-HT turnover rate was increased in the group of chicks that received orexin-A.

Monoamine concentrations from the telencephalons are shown in Table 3. NE concentration was increased both by orexin- $\mathrm{A}$ and time, and the time by treatment interaction was significant. MHPG concentrations were decreased by orexin-A, but were not affected by time. MHPG/NE was decreased by both orexin-A and time. For DA concentration itself, there was no significant difference, but orexin-A treatment and time were associated with increased DOPAC concentrations. The metabolic turnover rate of DOPAC/DA was increased by orexin-A but was not affected by time. 5-HT concentration was significantly decreased in orexin-A treated chicks at $60 \mathrm{~min}$ after injection. 5-HIAA concentrations were significantly increased by orexin-A but time was not a significant factor. There was a significant time by treatment interaction. The turnover rate of 5-HIAA/5-HT was significantly increased by orexin-A at $60 \mathrm{~min}$ after injection.

Previously there were no reports on the direct relationship between CORT and orexins in birds. da Silva et al. [32] reported that orexin induces stress-like behavior of pigeons but they did not conduct assays for plasma CORT concentrations. Therefore we measured plasma CORT concentrations in the present study. In chickens, CORT regulates blood glucose concentration and increases food intake [22]. In agreement with our previous report in chicks [8], da Silva et al. [32] also demonstrated that orexin affected neither food intake nor blood glucose concentration of pigeons. In the present study, orexin-A did not appear to stimulate the HPA axis of neonatal chicks (Experiment 1) because plasma CORT concentration was not affected. 
Therefore, the effects of orexins may not involve the HPA axis in avian species. This is contrary to rodent reports where orexin-A stimulates CORT release [28]. Thus, the orexin system appears to have been differentially selected during divergent evolution of birds and mammals.

We measured NE, DA and 5-HT because these three monoamines were previously reported to be activated by orexins [26]. Since orexin receptors are expressed throughout the brain with the exception of the cerebellum in the chicken [25], we used the telencephalon, mesencephalon and diencephalon to measure monoamine concentrations. All of the metabolic turnover rates for the three monoamines were increased after ICV injection of orexin-A in all brain regions assayed (Tables 1 to 3). These increased turnover rates associated with orexin-A may be involved with increased monoamine oxidase-A (MAO-A) and monoamine neuron activity. The former is supported by the reduction of monoamine content itself in the diencephalon (Table 1), where the effect of orexin peptides can be most potent because the dense innervation of orexin neurons are seen in this brain region in the house finch [33]. MAO-A degrades amine neurotransmitters, such as DA, NE, and 5-HT. The latter case is supported by the metabolite concentrations of each monoamine (MHPG, DOPAC and 5-HIAA) which are indicative of each associated neuron's activity.

Orexins activate noradrenergic neurons and inhibit REM sleep in rats [8]. Orexin neurons have the deepest innervations at the LC, a region of high NE content in both rats [8] and finches [33]. The LC is the main part of the brain where orexin exerts effects on NE [8]. In the rat brain, the LC expresses only the orexin receptor-1, but orexin and noradrenergic neurons have contact with each other here [1]. This was one confusing point of orexin's effects in birds. In rats, orexin neurons activate noradrenergic cell firing [8], and NE attenuates orexin neuron activity through $\mathrm{G}$ protein-coupled inwardly-rectifying potassium channel [18]. Although no direct effect of orexin on sympathetic nervous activity was shown in this experiment, some 
reports suggest that orexin causes activation of the sympathetic nervous system [3]. In the present experiment NE content itself was decreased in the diencephalon (Table 1), but the reverse was true in the telencephalon. According to Bungo et al. [2], central administration of NE induces narcolepsy in chicks. Thus, the lowered NE concentration in the diencephalon may be associated with the arousal effect by orexin-A. In the mesencephalon, MHPG (NE metabolites) content and turnover rate increased (Table 2). Similarly in the telencephalon, MHPG (Table 3) increased. This is contrary to a mouse report where cortex NE and 5-HT had no relationship with orexin [10], but NE was involved in the orexinergic system; Nishino et al. [23] demonstrated that orexin receptor-2-mutated dogs showed higher content of NE in the cortex than that of controls.

In mammals, dopaminergic neurons are involved in arousal and reward [19] and orexin is also involved in the reward system [9]. This system enhances feeding behavior in mammals, but in chicks orexin does not affect food intake [7]. Dopamine $\mathrm{D}_{1}$ and $\mathrm{D}_{2}$ antagonists can dose-dependently suppress orexin-induced hyperactivity and grooming behaviors [21]. Dopamine $\mathrm{D}_{1}$ and $\mathrm{D}_{2}$ receptors are indispensable in the mechanism of activity of modaphinil, a medicine used for the remedy of narcolepsy [27]. DA content itself was decreased in the diencephalon (Table 1). Similarly, NE was decreased, that may be related to the fact that NE is metabolized from DA. The content of DOPAC was decreased in the diencephalon (Table 1), but in other brain regions it was increased (Tables 2 and 3). The reason of this difference was not clear.

Orexin caused a $\mathrm{Ca}^{2+}$ transient increase at DRN serotonergic neurons and laterodorsal tegmental nucleus (LDT) acetylcholine [14]. There was a difference of neuronal reaction of DRN to orexin dependent on state of sleep-wakefulness, orexin excited 5-HT neurons during REM sleep, but not during wakefulness [34]. Analyzed regions were not restricted at this time; therefore there may be activated 5-HT neurons in other regions and nuclei. Orexin-A failed to increase release of 5-HT in the MRN, 
contrary to the result of the DRN [35]. Both the DRN and MRN are important brain regions in the reticular activating system, an arousal inducing one among the whole brain [19].

Another mechanism involved in arousal was the reticular formation system. The LC and DRN are the centers of the reticular formation system, and NE is one of the main factors of maintaining whole brain arousal [20]. Acetylcholine in the LDT is one of the main factors of this system [31]. NE neurons are responsible for maintaining arousal [20], however it induced narcolepsy in chicks [2]. Further studies remain to be done to clarify the mechanism of arousal.

In the present study, we showed that orexin-A induced arousal does not seem to be related to the HPA-axis in layer chicks, while monoamine neurons may contribute to arousal. 


\section{References}

[1] B.A. Baldo, R.A. Daniel, C.W. Berridge, A.E. Kelley, Overlapping distribution of orexin/hypocretin- and dopamine-beta-hydroxylase immunoreactive fibers in rat brain regions mediating arousal, motivation, and stress, J. Comp. Neurol. 464 (2003) 220-237.

[2] T. Bungo, S.I. Kawakami, A. Ohgushi, K. Sashihara, N. Saito, K. Sugahara, S. Hasegawa, D.M. Denbow, M. Furuse, Intracerebroventricular injection of fusaric acid attenuates the anorexia by glucagon-like peptide-1 in the neonatal chick, Pharmacol. Biochem. Behav. 70 (2001) 251-255.

[3] Y. Date, Y. Ueta, H. Yamashita, H. Yamaguchi, S. Matsukura, K. Kanagawa, T. Sakurai, M. Yanagisawa, M.Nakazato, Orexins, orexigenic hypothalamic peptides, interact with autonomic, neuroendocrine and neuroregulatory systems, Proc. Natl. Acad. Sci. U.S.A. 96 (1999) 748-753.

[4] J.L. Davis, D.T. Masuoka, L.K. Gerbrandt, A. Cherkin, Autoradiographic distribution of L-proline in chicks after intracerebral injection, Physiol. Behav. 22 (1978) 693-695.

[5] M.S. Duxon, J. Stretton, K. Starr, D.N.C. Jones, V. Holland, G. Riley, J. Jerman, S. Brough, D. Smart, A. Johns, W. Chan, R.A. Porter, N. Upton, Evidence that orexin-A-evoked grooming in the rat is mediated by orexin-1 (OX1) receptors, with downstream 5-HT2C receptor involvement, Psychopharmacology (Berl) 153 (2001) 203-209.

[6] M.W. Feltenstein, L.C. Lambdin, H.E. Webb, J.E. Warnick, S.I. Khan, I.A. Khan, E.O. Acevedo, K.J. Sufka, Corticosterone response in the chick separation-stress paradigm, Physiol. Behav. 78 (2003) 489-493.

[7] M. Furuse, R. Ando, T. Bungo, M. Shimojo, Y. Masuda, Intracerebroventricular injection of orexins does not stimulate food intake in neonatal chicks, Br. Poult. Sci. 
40 (1999) 698-700.

[8] J.J. Hagan, R.A. Leslie, S. Patel, M.L. Evans, T.A. Wattam, S. Holmes, C.D. Benham, S.G. Taylor, C. Routledge, P. Hemmati, R.P. Munton, T.E. Ashmeade, A.S. Shah, J.P. Hatcher, P.D. Hatcher, D.N. Jones, M.I. Smith, D.C. Ptper, A.J. Hunter, R.A. Porter, N. Upton, Orexin A activates locus coeruleus cell firing and increases arousal in the rat, Proc. Natl. Acad. Sci. U.S.A. 96 (1999) 10911-10916.

[9] G.C. Harris, M. Wimmer, G. Aston-Jones, A role for lateral hypothalamic orexin neurons in reward seeking, Nature 437 (2005) 556-559.

[10]Z-Y. Hong, Z-L. Huang, W-M. Qu, N. Eguchi, Orexin A promotes histamine, but not norepinephrine or serotonin, release in frontal cortex of mice, Acta Pharmacol. Sin. 26 (2005) 155-159.

[11] Y. Kabuki, K. Shigemi, K. Hamasu, M. Furuse, L-DOPA attenutates hyperactivity of Roborovskii hamsters, Behav. Pharmacol. 20 (2009) 260-264.

[12]S. Katayama, K. Hamasu, K. Shigemi, M.A., Cline, M. Furuse M, Intracerebroventricular injection of orexin- A, but not orexin-B, induces arousal of layer-type neonatal chicks, Comp. Biochem. Physiol. A 157 (2010) 132-135.

[13]K. Kitahama, I. Nagatsu, M. Geffard, T. Maeda, Distribution of dopamine-immunoreactive fibers in the rat brainstem, J. Chem. Neuroanat. 18 (2000) $1-9$.

[14]K.A. Kohlmeier, S. Watanabe, C.J. Tyler, S. Burlet C.S. Leonard, Dual orexin actions on dorsal raphe and laterodorsal tegmentum neurons: noisy cation current activation and selective enhancement of $\mathrm{Ca}^{2+}$ transients mediated by L-type calcium channels, J. Neurophysiol. 100 (2008) 2265-2281.

[15] T. Koutoku, H. Takahashi, S. Tomonaga, D. Oikawa, S. Saito, T. Tachibana, L.Han, K. Hayamizu, D.M. Denbow, F. Furuse, Central administration of phosphatidylserine attenuates isolation stress-induced behavior in chicks, Neurochem. Int. 47(2005)183-189. 
[16] W.J. Kuenzel, M. Masson, M., A stereotaxic Atlas of the Brain of the Chick (Gallusdomesticus). The Johns Hopkins University Press. (1978).

[17]L. de Lecca, T.S. Kilduff, C. Peyron, X. Gao, P.E. Foye, P.E. Danielson, C. Fukuhara, E.L. Battenberg, V.T. Gautvik, F.S. Bartlett II, W.N. Frankel, A.N. van den Pol, F.E. Bloom, K.M. Gautvik, J.G. Sutcliffe, The hypocretins: hypothalamus-specific peptides with neuroexcitatory activity, Proc. Natl. Acad. Sci. U.S.A. 95 (1998) 322-327.

[18] Y. Li, A.N. van den Pol, Direct and indirect inhibition by catecholamines of hypocretin/orexin neurons, J. Neurosci. 25 (2005) 173-183.

[19]D.B. Miller, J.P. O’Callagham, The pharmacology of wakefulness, Metabolism 55 (2006) 13-19.

[20]H.A. Mitchell D. Weinshenker, Good night and good luck: norepinephrine in sleep pharmacology, Biochem. Pharmacol. 79 (2009) 801-809.

[21] T. Nakamura, K. Uramura, T. Nambu, T. Yada, K. Goto, M. Yanagisawa, T. Sakurai, Orexin-induced hyperlocomotion and stereotypy are mediated by the dopaminergic system, Brain Res. 873 (2000) 181-187.

[22]A. Nasir, R.P. Moudgal, N.B. Singh, Involvement of corticosterone in food intake, food passage time and in vivo uptake of nutrients in the chicken (Gallus domesticus), Br. Poult. Sci. 40 (1999) 517-522.

[23] S. Nishino, N. Fujiki, B. Ripley, E. Sakurai, M. Kato, T. Watanabe, E. Mignot, K. Yanai, Decreased histamine content in hypocretin/orexin receptor-2 mutated narcoleptic dogs, Neurosci. Lett. 313 (2001) 125-128.

[24] T. Ohkubo, T. Boswell, S. Lumineau, Molecular cloning of chicken prepro-orexin cDNA and preferential expression in the chicken hypothalamus. Biochim. Biophys. Acta 1577 (2002) 476-480.

[25]T. Ohkubo, A. Tsukada, K. Shamoto, cDNA cloning of chicken orexin receptor and tissue distribution: sexually dimorphic expression in chicken gonads, J. Mol. 
Endocrinol. 31 (2003) 499-508.

[26] K. Ohno, T. Sakurai, Orexin neuronal circuitry: Role in the regulation of sleep and wakefulness, Front. Neuroendocrin. 29 (2008) 70-87.

[27]W-M. Qu, Z-L. Huang, X-H. Xu, N. Matsumoto, Y. Urade, Dopaminergic D1 and D2 receptors are essential for the arousal effect of modafinil, J. Neurosci. 28 (2008) 8462-8469.

[28] S.H. Russell, C.J. Small, C.L. Dakin, C.R. Abbott, D.G.A. Morgan, M.A. Ghatei, S.R. Bloom, The central effects of orexin-A in the hypothalamic-pituitary-adrenal axis in vivo and in vitro in male rats, J. Neuroendocrinol. 13 (2001) 561-566.

[29] S. Saito, T. Tachibana, Y.H. Choi, D.M. Denbow, M. Furuse, ICV CRF and isolation stress differentially enhance plasma corticosterone concentrations in layerand meat-type neonatal chicks, Comp. Biochem. Physiol. A 141 (2005) 305-309.

[30]T. Sakurai, A. Amemiya, M. Ishii, I. Matsuzaki, R.M. Chemilli, H. Tanaka, S.C. Williams, J.M. Richardson, G.P. Kozlowski, S. Wilson, J.R.S. Arch, R.E. Buckingham, A.C. Haynes, S.A. Carr, R.S. Annan, D.E. McNulty, W-S. Liu, J.A. Terrett, N.A. Elschourbagy, D.J. Bergsma, M. Yanagisawa, Orexins and orexin receptors: a family of hypothalamic neuropeptides and G protein-coupled receptors that regulate feeding behavior, Cell 92 (1998) 573-585.

[31]C.B. Saper, T.C. Chou, T.E. Scammell, The sleep switch: hypothalamic control of sleep and wakefulness, Trends Neurosci. 24 (2001) 726-731.

[32]E.S. da Silva, T.V. dos Santos, A.A. Hoeller, T.S. dos Santos, G.V. Pereira, C. Menegheli, A.I. Pezlin, M.M. dos Santos, M.S. Faria, M.A. Paschoalimi, J. Marino-Neto, Behavioral and metabolic effects of central injections of orexins/hypocretins in pigeons (Columba livia), Regul. Pept. 147 (2008) 9-18.

[33] K.G. Singletary, P. Deviche, C. Strand, Y. Delville, Distribution of orexin/hypocretin immunoreactivity in the brain of a male song bird, the house finch, Carpodacus mexicanus, J. Chem. Neuroanat. 32 (2006) 81-89. 
[34]K. Takahashi, Q-P. Wang, J-L. Guan, Y. Kayama, S. Shioda, Y. Koyama, State-depedent effects of orexins on the serotonergic dorsal raphe neurons in the rat, Regul. Pept. 126 (2005) 43-47.

[35]R. Tao, Z. Ma, J.T. McKenna, M.M. Thakkar, S. Winston, R.E. Strecker, R.W. McCarley, Differential effect of orexins (hypocretins) on serotonin release in the dorsal and median raphe nuclei of freely behaving rats, Neuroscience 141 (2006) 1101-1105.

[36]L. Yuan, Y. Ni, S. Barth, Y. Wang, R. Grossman, R. Zhao, Layer and broiler chicks exhibit similar hypothalamic expression of orexinergic neuropeptides but distinct expression of genes related to energy homeostasis and obesity, Brain Res. 1273 (2009) 18-28.

[37]R. Winsky-Sommerer, A. Yamanaka, S. Diano, E. Borok, A.J. Roberts, T. Sakurai, T.S. Kilduff, T.L. Horvath, L. de Lecca, Interaction between the corticotropin-releasing factor system and hypocretins (orexins): a novel circuit mediating stress response, J. Neurosci. 50 (2004) 11439-11448. 
Table 1. The effect of intracerebroventricular injection of orexin-A on the monoamine assessment of diencephalons

\begin{tabular}{|c|c|c|c|c|c|c|}
\hline $\begin{array}{c}\text { [38] Time after } \\
\text { injection } \\
(\mathrm{min})\end{array}$ & & & & & $F$ value & $P$ value \\
\hline Treatment & Control & Orexin & Control & Orexin & $\begin{array}{c}\text { Time }(1,24) \\
\text { Treatment }(1,24)\end{array}$ & $\begin{array}{c}\text { Time } \\
\text { Treatment }\end{array}$ \\
\hline NE & $7429 \pm 398$ & $6438 \pm 435$ & $6741 \pm 236$ & $5362 \pm 343$ & $\begin{array}{l}5.515 \\
9.967 \\
\end{array}$ & $\begin{array}{c}* \\
* * \\
\end{array}$ \\
\hline MHPG & $782 \pm 60$ & $877 \pm 30$ & $754 \pm 25$ & $768 \pm 74$ & $\begin{array}{l}1.616 \\
1.011 \\
\end{array}$ & $\begin{array}{l}\text { NS } \\
\text { NS }\end{array}$ \\
\hline MHPG/NE & $0.107 \pm 0.009$ & $0.139 \pm 0.007$ & $0.113 \pm 0.006$ & $0.143 \pm 0.011$ & $\begin{array}{c}0.299 \\
12.713 \\
\end{array}$ & $\begin{array}{r}\mathrm{NS} \\
* * \\
\end{array}$ \\
\hline DA & $1546 \pm 117$ & $1354 \pm 117$ & $1202 \pm 81$ & $862 \pm 65$ & $\begin{array}{c}16.981 \\
6.881 \\
\end{array}$ & ** \\
\hline DOPAC & $372 \pm 18$ & $366 \pm 14$ & $249 \pm 14$ & $262 \pm 36$ & $\begin{array}{c}24.582 \\
0.023 \\
\end{array}$ & $\begin{array}{l}* * \\
\mathrm{NS}\end{array}$ \\
\hline DOPAC/DA & $0.246 \pm 0.015$ & $0.281 \pm 0.022$ & $0.210 \pm 0.014$ & $0.297 \pm 0.022$ & $\begin{array}{c}0.277 \\
10.199 \\
\end{array}$ & $\begin{array}{l}\mathrm{NS} \\
* *\end{array}$ \\
\hline $5-\mathrm{HT}$ & $8058 \pm 456$ & $7067 \pm 434$ & $6584 \pm 195$ & $5283 \pm 289$ & $\begin{array}{l}18.223 \\
9.022 \\
\end{array}$ & $\begin{array}{l}* * \\
* *\end{array}$ \\
\hline 5-HIAA & $1897 \pm 32$ & $2253 \pm 122$ & $2218 \pm 90$ & $2479 \pm 226$ & $\begin{array}{l}4.062 \\
5.172 \\
\end{array}$ & $\begin{array}{c}\mathrm{NS} \\
* \\
\end{array}$ \\
\hline 5-HIAA/5-HT & $0.240 \pm 0.013$ & $0.322 \pm 0.018$ & $0.338 \pm 0.016$ & $0.466 \pm 0.023$ & $\begin{array}{l}45.902 \\
34.717 \\
\end{array}$ & $\begin{array}{l}* * \\
* * \\
\end{array}$ \\
\hline
\end{tabular}


Values are means \pm SEM in pg/g wet tissue. $\quad * *$ means $\mathrm{P}<0.01$, and $*<0.05$. The numbers of chicks were: saline 30 min 8 ; orexin 30 min 7 ; saline $60 \min 6$; orexin $60 \min 7$.

NE; norepinephrine, 5-HT; serotonin, DA; dopamine, MHPG; 3-methoxy-4-hydroxyphenylglycol, DOPAC; 3,4-dihydroxyphenylacetic acid, 5-HIAA; 5-hydroxyindoleacetic acid. 
Table 2. The effect of intracerebroventrucular injection of orexin-A on the monoamine assessment of mesencephalons

\begin{tabular}{|c|c|c|c|c|c|c|}
\hline $\begin{array}{l}\text { Time after } \\
\text { iniection (min) }\end{array}$ & \multicolumn{2}{|c|}{30} & \multicolumn{2}{|c|}{60} & \multirow{2}{*}{$\begin{array}{c}\text { F value } \\
\text { Time }(1,27) \\
\text { Treatment }(1,27)\end{array}$} & \multirow{2}{*}{$\begin{array}{c}\text { P value } \\
\text { Time } \\
\text { Treatment }\end{array}$} \\
\hline Treatment & Control & Orexin & Control & Orexin & & \\
\hline NE & $3445 \pm 184$ & $3114 \pm 274$ & $3054 \pm 137$ & $3293 \pm 198$ & $\begin{array}{l}0.279 \\
0.053\end{array}$ & $\begin{array}{l}\text { NS } \\
\text { NS }\end{array}$ \\
\hline MHPG & $537 \pm 53$ & $678 \pm 54$ & $778 \pm 52$ & $918 \pm 34$ & $\begin{array}{c}23.003 \\
7.833\end{array}$ & $\begin{array}{l}* * \\
* *\end{array}$ \\
\hline MHPG/NE & $0.164 \pm 0.024$ & $0.222 \pm 0.018$ & $0.254 \pm 0.012$ & $0.286 \pm 0.024$ & $\begin{array}{c}14.489 \\
4.873\end{array}$ & $\begin{array}{l}* * \\
*\end{array}$ \\
\hline DA & $175 \pm 23$ & $149 \pm 20$ & $192 \pm 7$ & $174 \pm 9$ & $\begin{array}{l}1.540 \\
1.669 \\
\end{array}$ & $\begin{array}{l}\text { NS } \\
\text { NS } \\
\end{array}$ \\
\hline DOPAC & $73 \pm 5$ & $78 \pm 8$ & $224 \pm 6$ & $225 \pm 5$ & $\begin{array}{c}622.214 \\
0.319 \\
\end{array}$ & $\begin{array}{l}* * * \\
\text { NS } \\
\end{array}$ \\
\hline DOPAC/DA & $0.453 \pm 0.048$ & $0.549 \pm 0.049$ & $1.177 \pm 0.046$ & $1.309 \pm 0.045$ & $\begin{array}{c}241.515 \\
5.666 \\
\end{array}$ & $\begin{array}{l}* * \\
* \\
\end{array}$ \\
\hline $5-\mathrm{HT}$ & $3510 \pm 149$ & $3323 \pm 73$ & - & - & - & NS \\
\hline 5-HIAA & $1543 \pm 66$ & $1901 \pm 76$ & $2013 \pm 38$ & $2363 \pm 69$ & $\begin{array}{l}53.674 \\
30.896 \\
\end{array}$ & $\begin{array}{l}* * \\
* * \\
\end{array}$ \\
\hline 5-HIAA/5-HT & $0.445 \pm 0.024$ & $0.565 \pm 0.029$ & - & - & - & $* *$ \\
\hline
\end{tabular}

Values are means \pm SEM in pg/g wet tissue. The numbers of chicks were: saline $30 \min 9$; orexin 30 min 7 ; saline 60 min 8 ; orexin 60 min 7 . 
** means $\mathrm{P}<0.01$, and $*<0.05$.

NE; norepinephrine, 5-HT; serotonin, DA; dopamine, MHPG; 3-methoxy-4-hydroxyphenylglycol, DOPAC; 3,4-dihydroxyphenylacetic acid, 5-HIAA; 5-hydroxyindoleacetic acid. 
Table 3. The effect of intracerebroventrucular injection of orexin-A on the monoamine assessment of telencephalons

\begin{tabular}{|c|c|c|c|c|c|c|}
\hline $\begin{array}{c}\text { Time after } \\
\text { injection ( } \mathrm{min})\end{array}$ & & & & & F value & $P$ value \\
\hline Treatment & Control & Orexin & Control & Orexin & $\begin{array}{c}\text { Time }(1,27) \\
\text { Treatment }(1,27)\end{array}$ & $\begin{array}{c}\text { Time } \\
\text { Treatment }\end{array}$ \\
\hline $\mathrm{NE}$ & $2488 \pm 48$ & $2616 \pm 107$ & $2893 \pm 119$ & $3870 \pm 191^{\dagger}$ & $\begin{array}{l}47.923 \\
21.275\end{array}$ & $\begin{array}{l}* * \\
* *\end{array}$ \\
\hline MHPG & $1053 \pm 73$ & $1373 \pm 84$ & $856 \pm 39$ & $1314 \pm 124$ & $\begin{array}{c}2.406 \\
22.160 \\
\end{array}$ & $\begin{array}{l}\mathrm{NS} \\
* * \\
\end{array}$ \\
\hline MHPG/NE & $0.423 \pm 0.027$ & $0.528 \pm 0.033$ & $0.299 \pm 0.017$ & $0.341 \pm 0.028$ & $\begin{array}{c}33.871 \\
7.494\end{array}$ & $\begin{array}{l}* * \\
* \\
\end{array}$ \\
\hline DA & $2932 \pm 102$ & $2960 \pm 130$ & $3137 \pm 81$ & $2825 \pm 118$ & $\begin{array}{l}0.103 \\
1.727 \\
\end{array}$ & $\begin{array}{l}\text { NS } \\
\text { NS }\end{array}$ \\
\hline DOPAC & $452 \pm 14$ & $564 \pm 27$ & $498 \pm 10$ & $614 \pm 13$ & $\begin{array}{r}7.985 \\
45.350 \\
\end{array}$ & $\begin{array}{l}* * \\
* * \\
\end{array}$ \\
\hline DOPAC/DA & $0.156 \pm 0.010$ & $0.193 \pm 0.012$ & $0.159 \pm 0.003$ & $0.220 \pm 0.011$ & $\begin{array}{c}2.425 \\
26.510 \\
\end{array}$ & $\begin{array}{l}\text { NS } \\
* *\end{array}$ \\
\hline $5-\mathrm{HT}$ & - & - & $4782 \pm 88$ & $3930 \pm 132$ & - & $* *$ \\
\hline 5-HIAA & $1698 \pm 36$ & $2218 \pm 74^{\dagger}$ & $1780 \pm 42$ & $2079 \pm 37^{\dagger}$ & $\begin{array}{c}0.355 \\
72.976 \\
\end{array}$ & $\begin{array}{l}\text { NS } \\
* *\end{array}$ \\
\hline 5-HIAA/5-HT & - & - & $0.374 \pm 0.014$ & $0.532 \pm 0.018$ & - & $* *$ \\
\hline
\end{tabular}

Values are means \pm SEM in pg/g wet tissue. The numbers of chicks were: saline $30 \min 9$; orexin $30 \min 7$; saline 60 min 8 ; orexin 60 min 7 . 
Values with $\dagger$ are significantly different within respective time at $\mathrm{p}<0.05$. $\quad * *$ means $\mathrm{P}<0.01$, and $*<0.05$.

NE; norepinephrine, 5-HT; serotonin, DA; dopamine, MHPG; 3-methoxy-4-hydroxyphenylglycol, DOPAC; 3,4-dihydroxyphenylacetic acid,

5-HIAA; 5-hydroxyindoleacetic acid. 